\title{
Ulcerative colitis relapse after Helicobacter pylori eradication in a 12-year-old boy with duodenal ulcer
}

\author{
Yuji Fujita ${ }^{* *} \mathbb{D}$, Keiichi Tominaga ${ }^{2}$, Takanao Tanaka², Takeshi Sugaya ${ }^{2}$ and Shigemi Yoshihara ${ }^{1}$
}

\begin{abstract}
Background: Helicobacter pylori (H. pylori) prevalence is lower in patients with inflammatory bowel disease (IBD) than in those without IBD, suggesting that $H$. pylori plays a protective role in IBD. It has been reported that IBD may occur due to H. pylori eradication; however, it is unclear whether $H$. pylori eradication increases the incidence of IBD. Moreover, the effect of $H$. pylori eradication on IBD activity is unclear.

Case presentation: An 11-year-old boy diagnosed with ulcerative colitis (UC) was in clinical remission, with treatment involving 5-aminosalicylic acid. Fecal calprotectin (FC) level had decreased to $33.2 \mathrm{mg} / \mathrm{kg}$, indicating mucosal healing. At age 12, he experienced epigastric pain on an empty stomach, which was relieved with dietary intake. His FC level was elevated without UC symptoms, such as diarrhea and bloody stools. He was diagnosed with H. pylori duodenal ulcer. H. pylori eradication (clarithromycin and amoxicillin for 7 days and a proton-pump inhibitor) led to symptom improvement the day after treatment initiation. However, he developed diarrhea and his FC level remained high despite improvement in duodenal ulcer symptoms and endoscopic findings of H. pylori eradication. Colonoscopy results indicated $U C$ relapse.
\end{abstract}

Conclusions: H. pylori eradication may worsen UC activity. However, further studies are required as this case report involved only one pediatric patient with increased UC activity after H. pylori eradication.

Keywords: Fecal calprotectin, Helicobacter pylori, Ulcerative colitis

\section{Background}

The prevalence of inflammatory bowel disease (IBD), including ulcerative colitis (UC) and Crohn's disease, has increased worldwide. [1] Its pathogenesis involves gut microbiota, [2] including Helicobacter pylori (H. pylori). The prevalence of $H$. pylori is lower in patients with IBD than in those without IBD, which suggests $H$. pylori plays a protective role in the development of IBD. [3, 4] It has previously been reported that IBD may occur due to $H$. pylori eradication [5-7]; however, whether $H$. pylori

\footnotetext{
${ }^{*}$ Correspondence: fujitay@dokkyomed.ac.jp

1 Department of Pediatrics, Dokkyo Medical University, 880 Kitakobayashi,

Mibu, Shimotsuga, Tochigi 321-0293, Japan

Full list of author information is available at the end of the article
}

eradication increases the incidence of IBD as well as the effect of $H$. pylori eradication on IBD activity remains unclear. We describe a pediatric case of UC, worsened through $H$. pylori eradication for the treatment of duodenal ulcer.

\section{Case presentation}

An 11-year-old boy consulted a family doctor for bloody diarrhea. The patient had no specific medical or family history. A colonoscopy from the rectum to the sigmoid colon led to the diagnosis of pediatric UC with a pediatric ulcerative colitis activity index (PUCAI) of 30. He was administered 5-aminosalicylic acid (5-ASA) suppositories ( $1 \mathrm{~g} /$ day $)$ and was referred to our hospital for subsequent treatment. His symptoms promptly improved 
to a PUCAI of 5 . His blood examination results were unremarkable but the fecal calprotectin (FC) level was elevated to $3,190 \mathrm{mg} / \mathrm{kg}$. A complete colonoscopy was performed, which revealed inflammatory findings from the rectum to the transverse colon. Moreover, the cecum and ascending colon showed loss of vascular permeability and adherent purulent mucus (Fig. 1a, b). The patient was prescribed oral 5-ASA (3,000 mg/day). The FC level gradually decreased to $33.2 \mathrm{mg} / \mathrm{kg}$ by week 15 (Fig. 2).

At 12 years old, he complained of epigastric pain on an empty stomach, which was relieved with dietary intake (week 19). He reported no UC symptoms, including diarrhea and bloody stools (PUCAI, 0); however, an elevated FC level was noted (week 20). Esophagogastroduodenoscopy (EGD) findings indicated an A1 ulcer on the lower wall of the duodenal bulb (Fig. 3A). A rapid urease test was positive, and he was diagnosed with a duodenal ulcer due to $H$. pylori infection. The $H$. pylori infection was treated using clarithromycin and amoxicillin for 7 days and a proton-pump inhibitor. The patient's symptoms improved the day after treatment initiation. In week 33, an EGD was performed to evaluate the therapeutic effect. The duodenal ulcer had healed, and scarring was observed (Fig. 3B).

The FC level remained high despite improvement of duodenal ulcer symptoms and endoscopic findings of $H$. pylori eradication. The patient subsequently developed diarrhea (PUCAI, 10) in week 35 and a UC relapse was considered. Cytomegalovirus antibody, antigenemia, and tuberculosis (T-SPOT assay) tests were negative. Colonoscopy showed small aphthae and edematous mucosa throughout the colon in week 36 (Fig. 1C, D). Histopathological examination revealed UC lesions grades 3-5 based on the Matts classification. The patient was diagnosed with a UC relapse, and the 5-ASA dosage was increased to $4,000 \mathrm{mg} /$ day $(100 \mathrm{mg} / \mathrm{kg} /$ day $)$.

\section{Discussion and conclusion}

H. pylori has been considered protective against immune-mediated diseases, including IBD. However, it has additionally been associated with peptic ulcers and gastric cancer. H. pylori eradication may be more effective in preventing the development of gastric cancer in people of Asian ethnicity than in those of

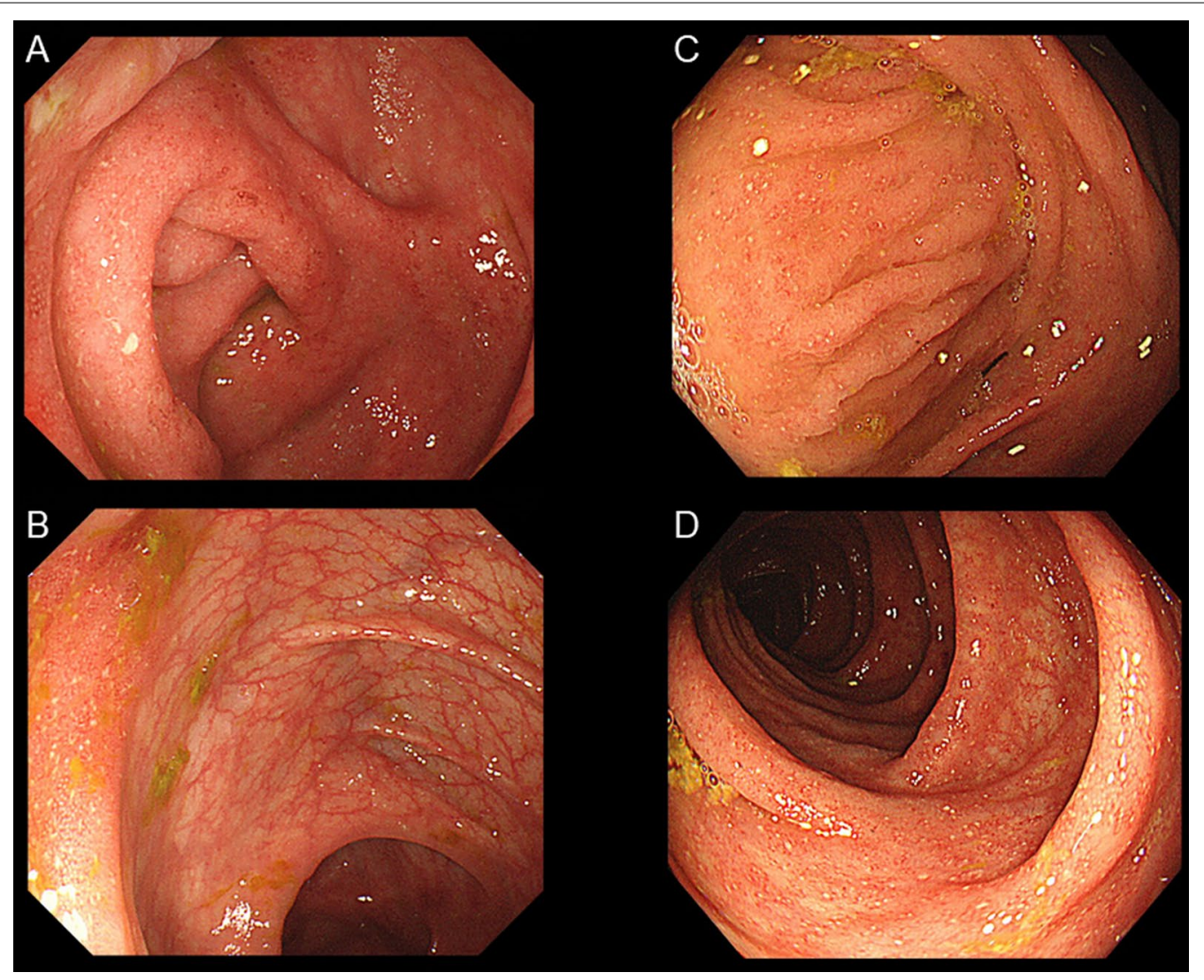

Fig. 1 Colonoscopy findings. The cecum (a) and ascending colon (b) at the time of diagnosing ulcerative colitis with slight inflammation from the rectum to the transverse colon. The cecum and ascending colon show loss of vascular permeability and adherent purulent mucus. At the time of ulcerative colitis relapse, the cecum (c) and ascending colon (d) had small aphthae and edematous mucosa 


\begin{tabular}{|c|c|c|c|c|c|c|c|c|}
\hline $\begin{array}{c}\text { 5-aminosalicylic } \\
\text { acid } \\
\text { suppositories }\end{array}$ & \multicolumn{8}{|c|}{1000 mg/day } \\
\hline \multirow{5}{*}{$\begin{array}{c}\text { 5-aminosalicylic } \\
\text { acid } \\
\text { orally }\end{array}$} & \multicolumn{8}{|c|}{$3000 \mathrm{mg} / \mathrm{day}$} \\
\hline & \multicolumn{8}{|c|}{ Proton pump inhibitor } \\
\hline & \multicolumn{8}{|c|}{ Clarithromycin } \\
\hline & \multicolumn{8}{|c|}{ Amoxicillin } \\
\hline & Week 0 & Week 4 & Week 10 & Week 15 & Week 20 & Week 29 & Week 33 & \\
\hline $\begin{array}{l}\text { Pediatric ulcerative } \\
\text { Colitis activity index }\end{array}$ & 5 & 0 & 0 & 0 & 0 & 0 & 0 & \\
\hline $\begin{array}{l}\text { C-reactive protein } \\
\text { (mg/dL) }\end{array}$ & $<0.01$ & $<0.01$ & $<0.01$ & $<0.01$ & $<0.01$ & $<0.01$ & $<0.01$ & \\
\hline $\begin{array}{l}\text { Enythrocyte } \\
\text { sedimentation rate } \\
\text { (mm/hr) }\end{array}$ & 7 & 3 & 8 & 7 & 10 & 10 & 10 & \\
\hline $\begin{array}{l}\text { Leucine-Rich Alpha-2 } \\
\text { Glycoprotein } \\
(\mu / \mathrm{gL})\end{array}$ & - & 8.9 & 13.3 & 10.2 & 16.8 & 13.7 & 10.5 & \\
\hline $\begin{array}{l}\text { Fecal calprotectin } \\
(\mathrm{mg} / \mathrm{kg})\end{array}$ & 3190 & 571 & 179 & 33.2 & 1770 & 4860 & 3120 & \\
\hline Colonoscopy & 1 & & & & & & & 2 \\
\hline
\end{tabular}

Fig. 2 A timeline showing the patient's disease course in terms of pediatric ulcerative colitis activity index values, C-reactive protein, erythrocyte sedimentation rate, leucine-rich alpha-2 glycoprotein, and fecal calprotectin levels at different time points. The timeline and duration of various treatments administered for ulcerative colitis and Helicobacter pylori are indicated. The time points indicating when the colonoscopy and the esophagogastroduodenoscopy were undertaken are also shown

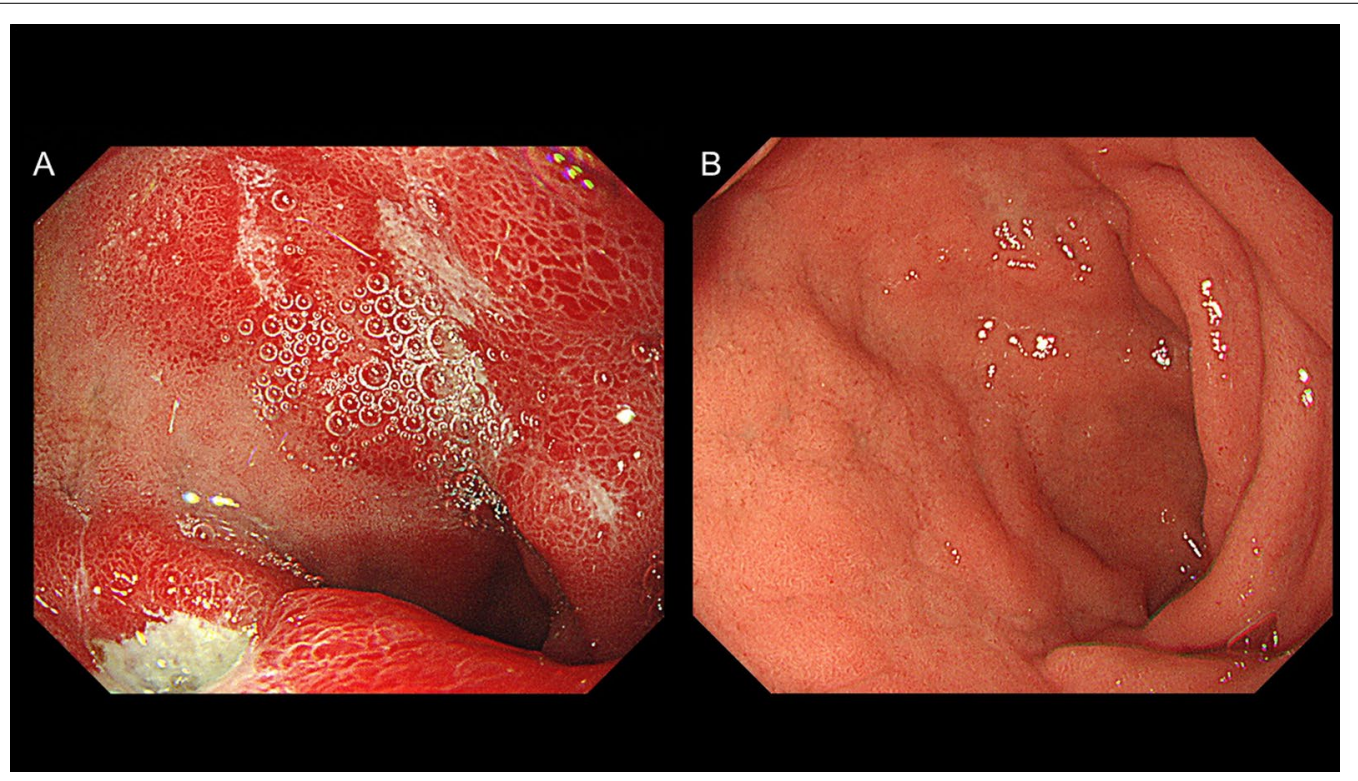

Fig. 3 Esophagogastroduodenoscopy. a At the time of duodenal ulcer diagnosis, esophagogastroduodenoscopy findings revealed an A1 ulcer on the lower wall of the duodenal bulb. b Three months after Helicobacter pylori treatment, esophagogastroduodenoscopy findings indicated healing of the duodenal ulcer and scarring

European ethnicity; therefore, most patients of Asian ethnicity actively undergo $H$. pylori treatment. [8] In Asia, the incidence of IBD has been increasing, [9] and theoretically, active eradication of $H$. pylori may have a role in this observed increase. Several studies have reported the development of IBD after eradication of $H$. 
pylori. [5-7] Furthermore, there is a report that there is an inverse association between $H$. pylori and UC severity. [10] However, data concerning the effect of $H$. pylori eradication on IBD activity are limited. A multicenter retrospective cohort study showed that $H$. pylori eradication did not worsen IBD activity. [11] However, there have been no reports involving pediatric patients with IBD. We report a pediatric patient with worsened UC activity following the eradication of $H$. pylori.

The mechanism by which $H$. pylori acts protectively on IBD is unclear; however, there are various reports using mouse models. Zhang et al. reported that $H$. pylori had a protective action in mice with chronic experimental colitis. They considered that this protective mechanism involved $H$. pylori colonization increasing regulatory $\mathrm{T}$ cells and interleukin (IL)-10 and suppressing IL-17 producing effector T-helper cells. [12] Gravina et al. reported that $\mathrm{Hp}(2-20)$ derived from $\mathrm{H}$. pylori accelerates the healing of not only gastric mucosa but also inflamed colonic mucosa in 2-, 4-, 6-trinitrobenzenesulfonic acid-induced colitis, and the effect is considered to be associated with the reduction of inflammatory mediators such as tumor necrosis factor- $\alpha$ in colonic tissue. [13] Chen et al. reported that NLRP12 decreased MCP-1 and MIP- $1 \alpha$ expression in intestinal epithelial cells from the analysis of the exomes derived from $H$. pylori-infected IBD patients, and this report showed NLRP12 has a negative correlation with the disease activity in pediatric IBD patients. [14] Further research on the function of H. pylori in IBD patients is required.

In our patient, endoscopic mucosal healing was not confirmed after the initial 5-ASA treatment. However, an FC level $<250 \mathrm{mg} / \mathrm{kg}$ is indicative of endoscopic and histological mucosal healing. [15] Based on these findings, we considered that our patient had achieved remission after the initial treatment. We noted elevation in his FC level following the onset of the duodenal ulcer; however, it was unclear whether this elevated FC level due to the duodenal ulcer or to UC relapse. However, there were no clinical symptoms of UC. Three months after $H$. pylori eradication, the patient had an increased FC level, and he gradually developed diarrhea. Therefore, the elevated FC level was considered to be due to UC activity. The FC level is the most helpful biomarker of endoscopic disease activity. [16] No other hematological biomarkers, including leucine-rich alpha 2 glycoprotein, are considered helpful in evaluating IBD activity. [17] FC monitoring following $H$. pylori eradication may help to detect endoscopic and histological relapse prior to clinical relapse. Endoscopic and histological remission in addition to clinical remission should be confirmed in patients with H. pylori-induced peptic ulcer cases.18.
To date, no studies concerning pediatric IBD have evaluated the $\mathrm{FC}$ level prior to and post $H$. pylori eradication. Measuring the FC level is non-invasive and allows early detection of relapse during the asymptomatic phase. Further studies are required to determine the effect of $H$. pylori eradication in relation to pediatric IBD activity.

\section{Abbreviations}

EGD: Esophagogastroduodenoscopy; FC: Fecal calprotectin; H. pylori:: Helicobacter pylori; IBD: Inflammatory bowel disease; IL: Interleukin; PUCAI: Pediatric Ulcerative Colitis Activity Index; UC: Ulcerative colitis.

\section{Acknowledgements}

We would like to thank Editage (www.editage.com) for English language editing.

\section{Authors' contributions}

YF collected and analyzed the data and drafted and revised the initial manuscript. KT, TT, TS, and SY interpreted all the data and critically revised the manuscript for important intellectual content. All the authors have read and approved the final manuscript and agreed to be accountable for all aspects of the work.

\section{Funding}

No funding was received for the work.

\section{Availability of data and materials}

Data sharing is not applicable to this article as no datasets were generated or analyzed during the current study.

\section{Declarations}

Ethical approval and consent to participate

Consent to participate is not applicable to this article as it is a case report.

\section{Consent for publication}

Written informed consent was obtained from the parents of the patient for publication of this case report and any accompanying images. A copy of the written consent is available for review by the Editor of this journal.

\section{Competing interests}

The authors declare that they have no competing interests.

\section{Author details}

'Department of Pediatrics, Dokkyo Medical University, 880 Kitakobayashi, Mibu, Shimotsuga, Tochigi 321-0293, Japan. ${ }^{2}$ Department of Gastroenterology, Dokkyo Medical University, Tochigi, Japan.

Received: 27 April 2021 Accepted: 2 November 2021

Published online: 10 November 2021

\section{References}

1. Ng SC, Shi HY, Hamidi N, Underwood FE, Tang W, Benchimol El, et al. Worldwide incidence and prevalence of inflammatory bowel disease in the $21^{\text {st }}$ century: a systematic review of population-based studies. Lancet. 2017:390:2769-78.

2. Kostic $A D$, Xavier RJ, Gevers D. The microbiome in inflammatory bowel disease: current status and the future ahead. Gastroenterology. 2014;146:1489-99.

3. Sonnenberg A, Genta RM. Low prevalence of Helicobacter pylori infection among patients with inflammatory bowel disease. Aliment Pharmacol Ther. 2012;35:469-76. 
4. Gastano-Rodrigeuez N, Kaakoush NO, Lee WS, Mitchell HM. Dual role of Helicobacter and Campylobacter species in IBD: a systematic review and meta-analysis. Gut. 2017;66:235-49.

5. Tursi A. Onset of Crohn's disease after Helicobacter pylori eradication. Inflamm Bowel Dis. 2006;12:1008-9.

6. Jovanovic IR, Milosavjevic TN, Jankovic GP, Micev MM, Dugalic PD, Saranovic D, et al. Clinical onset of the Crohn's disease after eradication therapy of Helicobacter pylori infection. Does Helicobacter pylori infection interact with natural history of inflammatory bowel diseases? Med Sci Monit. 2001;7:137-41.

7. Chiba M, Tsuji T, Takahashi K, Komatsu M, Sugawara T, Ono I. Onset of ulcerative colitis after Helicobacter pylori eradication therapy: A case report. Perm J. 2016;20:e115-8.

8. Ford AC, Forman D, Hunt RH, Yuan Y, Moayyedi P. Helicobacter pylori eradication therapy to prevent gastric cancer in healthy asymptomatic infected individuals: systematic review and meta-analysis of randomized controlled trials. BMJ. 2014;348:93174.

9. Thia KT, Loftus EV, Sandborn WJ, Yang SK. An update on the epidemiology of inflammatory bowel disease in Asia. Am J Gastroenterol. 2008;103:3167-82.

10. Jin X, Chen YP, Chen SH, Xiang Z. Association between Helicobacter Pylori infection and ulcerative colitis - - a case control study from China. Int J Med Sci. 2013;10:1479-84.

11. Shinzaki S, Fujii T, Bamba S, Ogawa M, Kobayashi T, Oshita M, et al. Seven days triple therapy for eradication of Helicobacter pylori does not alter the disease activity of patients with inflammatory bowel disease. Intest Res. 2018;16:609-18.

12. Zhang H, Dai Y, Liu Y, Wu T, Li J, Wang X, et al. Helicobacter pylori colonization protects against chronic experimental colitis by regulating Th17/Treg balance. Inflamm Bowel Dis. 2018;24:1481-92.
13. Gravina AG, Prevete N, Tuccillo C, Musis CD, Romano L, Federico A, et al. Peptide Hp(2-20) accelerates healing of TNBS-induced colitis in the rat. United European Gastroenterol J. 2018;6:1428-36.

14. Chen Y, Huang J, Li H, Li P, Xu C. Serum exomes derived from Hp-positive gastritis patients inhibit MCP-1 and MIP-1a expression via NLRP12-Notch signaling pathway in intestinal epithelial cells and improve DSS-induced colitis in mice. Int Immunopharmacol. 2020;88:107012.

15. Zittan E, Kelly OB, Kirsch R, Milgrom R, Burns J, Nguyen GC, et al. Low fecal calprotectin correlates with histological remission and mucosal healing in ulcerative colitis and colonic Crohn's disease. Inflamm Bowel Dis. 2016;22:623-30.

16. Schoepfer AM, Beglinger C, Straumann A, Safroneeva E, Romero Y, Armstrong D, et al. Fecal calprotectin more accurately reflects endoscopic activity of ulcerative colitis than Lichtiger Index, C-reactive protein, platelets, hemoglobin, and blood leukocytes. Inflamma Bowel Dis. 2013;19:332-41.

17. Yoshimura T, Mitsuyama K, Sakemi R, Takedatsu H, Yoshioka S, Kuwaki $K$, et al. Evaluation of serum leucine-rich alpha-2 glycoprotein as a new inflammatory biomarker of inflammatory bowel disease. Mediators Inflamm. 2021;8825374.

18. Ungaro R, Colombel JF, Lissoos T, Peyrin-Biroulet L. A treat-to-target update in ulcerative colitis: A systematic review. Am J Gastroenterol. $2019 ; 114: 874-83$

\section{Publisher's Note}

Springer Nature remains neutral with regard to jurisdictional claims in published maps and institutional affiliations.
Ready to submit your research? Choose BMC and benefit from:

- fast, convenient online submission

- thorough peer review by experienced researchers in your field

- rapid publication on acceptance

- support for research data, including large and complex data types

- gold Open Access which fosters wider collaboration and increased citations

- maximum visibility for your research: over 100M website views per year

At BMC, research is always in progress.

Learn more biomedcentral.com/submissions 